\title{
Letter to editor: "Sim life model: introducing a new teaching device in endocrine surgery simulation"
}

\author{
Yuvraj Devgan $^{1} \cdot$ Sarrah Idrees $^{1} \cdot$ Sabaretnam Mayilvaganan ${ }^{1}$ (B)
}

Received: 23 November 2021 / Accepted: 6 December 2021 / Published online: 10 January 2022

(C) Italian Society of Surgery (SIC) 2021

We read with interest the article "Sim life model: introducing a new teaching device in endocrine surgery simulation" by Donatini et al. [1], and this article was presented and discussed in our departmental journal club. We congratulate the authors on their effort to introduce a new teaching device and this may have lasting effect on the teaching and training of endocrine surgery trainees including theoretical part of surgical training, surgical communication, and counseling [2]. We also agree with the authors that some endocrine surgical procedures are rare, since tumors such as adrenocortical carcinoma and insulinoma are rare tumors and the exposure of trainee to such tumors during their stipulated training time may not be possible. In such situations, these simulation models may provide the necessary expertise for the knife happy surgeon to handle with confidence such procedures, later when encounter such rare tumors. We also agree with their training evaluation methodology. We propose as endocrine surgery involves endocrinology knowledge and its application in day-to-day management of these metabolically deranged patients, simulation models for interpretation of thyroid function tests, interpretation of bone mineral density reports, and also models for management of endocrine emergencies like hypercalcemic crisis, hypertensive crisis due to hypercatecholism, thyrotoxic storm, and myxedema coma to name a few and management of post-operative issues like post-thyroidectomy stridor, post-thyroidectomy bleed, and post-thyroidectomy hypocalcemia can be useful for young endocrine surgical trainees for whom endocrine surgical principles can still remain a myth.

We have few queries which may interest future readers. Did the authors have a pre-simulation scoring system for various surgeries so that post-simulation effect on trainees could be clearly ascertained? Did the trainees before simulation procedures undergo any kind of video demonstration or lecture by faculty regarding the procedure? Did the presimulation surgical experience affect the score during simulation? We suggest authors to kindly consider these suggestions, and again, we congratulate on their novel simulation teaching initiative for endocrine surgical training.

Thanks for comment on these issues.

\section{Declarations}

Conflict of interest No conflict of interest.

Research involving human participants and/or animals Not applicable. Informed consent Not applicable.

\section{References}

1. Donatini G, Bakkar S, Leclere FM, Dib W, Suaud S, Oriot D, Breque C, Richer JP, Faure JP, Danion J (2021) SimLife model: introducing a new teaching device in endocrine surgery simulation. Update Surg 73(1):289-295

2. Bjerrum F, Thomsen AS, Nayahangan LJ, Konge L (2018) Surgical simulation: current practices and future perspectives for technical skills training. Med Teach 40(7):668-675

Publisher's Note Springer Nature remains neutral with regard to jurisdictional claims in published maps and institutional affiliations.
Sabaretnam Mayilvaganan

drretnam@gmail.com

1 Department of Endocrine and Breast Surgery, Sanjay Gandhi

Postgraduate Institute of Medical Sciences, Lucknow, India 